\title{
Excess Risk of Temporomandibular Disorder Associated with Cigarette Smoking in Young Adults
}

\author{
Anne E. Sanders ${ }^{1}$, Gary D. Slade ${ }^{1}$, William Maixner ${ }^{2}$, Andrea G. Nackley ${ }^{2}$, Luda \\ Diatchenko ${ }^{2}$, Kunthel $\mathrm{By}^{3}$, and Vanessa E. Miller ${ }^{2}$ \\ ${ }^{1}$ Department of Dental Ecology, School of Dentistry, University of North Carolina at Chapel Hill \\ ${ }^{2}$ Center for Neurosensory Disorders, University of North Carolina at Chapel Hill \\ ${ }^{3}$ Department of Biostatistics, Gillings School of Global Public Health, University of North Carolina \\ at Chapel Hill
}

\begin{abstract}
Evidence suggests that the effect of cigarette smoking on chronic pain is stronger in younger than older adults. This case control study investigated whether age modified an effect of smoking on temporomandibular disorder (TMD) in 299 females aged 18-60 years. It also investigated the extent to which this relationship was explained by psychological profile, inflammatory response and allergy. Cases were defined using the Research Diagnostic Criteria for Temporomandibular Disorders based on clinical examination. Psychological profile was evaluated using standardized instruments. Inflammatory response was evaluated with 11 cytokines isolated in plasma. History of allergy conditions was self-reported. Odds ratios (OR) for the effect of smoking were calculated using binary logistic regression. Stratified analyses and the likelihood ratio test examined effect modification by smoking. Compared to non-smokers, ever smokers aged $<30$ years had higher odds of TMD (OR $=4.14,95 \%$ CI: $1.57,11.35)$ than older adults ( $\mathrm{OR}=1.23,95 \%$ CI: $0.55,2.78)$ $(P($ effect modification $)=0.038)$. Adjustment for psychological profile, cytokines and history of allergy-like conditions attenuated the effect by $45 \%$ to statistical non-significance. The main finding was reproduced with secondary analyses of two nationally-representative surveys of adults conducted in the U.S. and Australia.
\end{abstract}

\section{Keywords}

Epidemiology; case-control study; temporomandibular joint disorder; psychological stress; allergy and hypersensitivity, cytokines

\section{Introduction}

Tobacco smoke plays a role in several chronic pain conditions. ${ }^{29,41,48,52,71}$ A metaanalysis of the association between smoking and low back pain from 27 cross-sectional and 13 cohort studies showed that, compared to non-smokers, smokers had greater risk of pain.

(C) 2011 The American Pain Society. Published by Elsevier Inc. All rights reserved.

Corresponding author: Anne E. Sanders Department of Dental Ecology School of Dentistry University of North Carolina at Chapel Hill Campus Box 7450 Chapel Hill, NC 27599-7450 Phone: (919) 843-0825 Fax: (919) 843-1170 anne_sanders@ dentistry.unc.edu.

Publisher's Disclaimer: This is a PDF file of an unedited manuscript that has been accepted for publication. As a service to our customers we are providing this early version of the manuscript. The manuscript will undergo copyediting, typesetting, and review of the resulting proof before it is published in its final citable form. Please note that during the production process errors may be discovered which could affect the content, and all legal disclaimers that apply to the journal pertain. 
There was a dose-response relation in which greater exposure to tobacco was associated with greater risk of pain..$^{55}$ The 13 prospective cohort studies in this meta-analysis helped clarify temporal ambiguity, showing that smoking preceded pain onset in current and former smokers. Of particular interest was that the effect of smoking on pain incidence was greater in younger than older adults.

Headache is another pain condition in which the effect of smoking is more pronounced at younger age. The Head-HUNT Study, a Norwegian population-based study of 51,383 adults, found an effect of smoking on headache was modified by age, peaking around 30 years and then declining (P effect modification <0.0001). ${ }^{1}$ In a New Zealand birth cohort a two-fold risk of headache due to smoking present in adolescence, was no longer apparent when the cohort was aged 26 years. ${ }^{63}$

Three studies have examined smoking in temporomandibular disorder (TMD) ${ }^{36,65,66}$ but none has examined whether its effect differs by age. Accounting for smoking is important in TMD research not only because of smoking's potential causal role, but also because smoking may account for effects of other TMD risk factors including perceived stress, anxiety, and depression. ${ }^{10,12,35,49,50}$

Psychological stress is well recognized for its relationship with TMD. Less well investigated are the roles of allergy and inflammation. This is surprising given that allergy is comorbid with several idiopathic pain conditions including fibromyalgia, ${ }^{8}$ low back pain, ${ }^{24}$ headache, ${ }^{2}$ vulvodynia ${ }^{21}$ and irritable bowel syndrome. ${ }^{61}$ In addition elevated levels of inflammatory cytokines are associated with headache, ${ }^{27}$ fibromyalgia ${ }^{6,8}$ and irritable bowel syndrome. ${ }^{5}$ One possible mediator is monocyte chemoattractant protein-1 (MCP-1). This chemokine induces histamine release from basophils ${ }^{7}$ and contributes to the pathogenesis of allergic disorders. ${ }^{23,69}$ MCP-1 concentration was 2.3-fold higher in synovial fluids of TMD cases than non-cases, although differences failed to reach statistical significance. ${ }^{44}$

Whether young smokers are more susceptible than nonsmokers and older adults to pain mediated by an inflammatory or allergy pathway is unknown. What is established is that smoking is associated with the production of pro-inflammatory cytokines and inhibition anti-inflammatory cytokines. Smoking increases sensitization to allergens ${ }^{26}$ and facilitates permeability of the respiratory epithelium. ${ }^{17}$ Serum immunoglobulin E (IgE) levels are higher in smokers than non-smokers ${ }^{60}$ and IgE levels decrease dramatically with age. The age-related reduction is especially noticeable in atopic females, until 35 years after which further age-related declines are not apparent. ${ }^{4}$ Taken together, the findings imply that smoking may influence pain either through allergic or inflammatory pathways, or both.

To clarify these relationships, this study tested whether age modified a relation between smoking and TMD. We hypothesized that an effect of smoking on TMD was stronger in younger adults. If confirmed, the second aim was to quantify the extent to which psychological vulnerability, allergy-related conditions, and plasma cytokine levels attenuated the smoking-related effect.

\section{Materials and Methods}

This study was approved by the Biomedical Institutional Review Board of the University of North Carolina at Chapel Hill (UNC-CH). Written informed consent was obtained from all study participants.

\section{Study design and recruitment}

Data for this analysis were from a case-control study of risk factors for chronic TMD. 
All study participants were female, aged between 18 and 60 years and self-identified as Caucasian. Sampling was limited to females because prevalence of TMD is greater in females than males. The rationale for limiting inclusion to a single racial group was to simplify interpretation of genetic findings since one objective of the study is to investigate genetic risk factors for TMD. All study participants were recruited from the Central North Carolina community with the use of fliers, mass informational emails sent to the UNC-CH population, and advertisements in local newspapers, radio and at the Orofacial Pain Clinic at the UNC-CH School of Dentistry between 2005 and 2009.

All potential participants were screened by a telephone interview to exclude those with diagnoses of any one of diabetes, kidney disease, heart failure, chronic respiratory disease, epilepsy or seizure disorder, or high blood pressure not controlled with medication. Also excluded were those who were pregnant, nursing, undergoing orthodontic treatment, renal dialysis, radiation or chemotherapy as well as persons with trauma or surgery on the head, face or neck within the last six months.

A medical history was recorded for all subjects prior to a clinical examination. Examinations were performed by one of ten examiners trained in the examination protocol and calibrated for the reliability and validity of their diagnostic decisions every six months. Cases were persons who met Research Diagnostic Criteria for Temporomandibular Disorders (TMD) ${ }^{15}$ for myalgia, arthralgia or both, based on a In summary, cases were people who reported a six-month history of pain in the temporomandibular structures, with at least 5 days of such pain in the month preceding the examination and where examiners found at least three muscle groups in the temporomandibular region that were tender to palpation or jaw maneuver. The threshold of six months was chosen to be consistent with the classification for chronic pain for research purposes described in the IASP Task Force on Taxonomy. ${ }^{38}$ Controls reported no history of orofacial pain within the preceding six months and no prior diagnosis for TMD. Additionally, their examination confirmed that they did not have arthralgia or myalgia.

\section{Smoking status}

Lifetime smoking status was evaluated with the question widely used in major US population surveys including the National Health Interview Survey (NHIS), the National Health and Nutrition Examination Survey (NHANES) and the Behavioral Risk Factor Surveillance Survey (BRFSS): Have you smoked at least 100 cigarettes in your entire life?" Those with a negative response were classified as lifetime non-smokers. Those with an affirmative response were further classified as current or former smokers.

\section{Allergy-related conditions}

A medical history questionnaire presented a list of conditions against which participants checked "Yes" if they had ever had the condition; otherwise they checked "No". Conditions included dermal mucocutaneous conditions (skin rashes), respiratory conditions (sinus trouble, allergies or hives) and any use of antihistamine medication.

\section{Cytokines}

Cytokines are small intracellular regulatory proteins that play a major role in immune response as well as cell growth and tissue repair. ${ }^{18,40,53}$ Peripheral blood samples were collected and plasma was isolated using multiplex technology to measure 11 cytokines (R\&D Systems; Minneapolis, MN). Cytokines included on the multiplex panel were: vascular endothelial growth factor (VEGF); fibroblast growth factor (FGF); interleukin-1 receptor antagonist (IL-1Ra); monocyte chemoattractant protein-1 (MCP-1); interleukin-6 (IL-6); interleukin (IL-8); epithelial neutrophil-activating protein 78 (ENA-78), tumor 
necrosis factor-alpha (TNF $\alpha)$, macrophage inflammatory protein 1 alpha (MIP-1 $\alpha$ ), granulocyte-colony stimulating factor(G-CSF) and thrombopoietin (TPO). Concentrations of the 11 cytokines were standardized and each was tested for its strength of their association with TMD in logistic regression. Eight of these had significantly elevated concentrations in TMD cases compared with controls $(\mathrm{P}<0.05)$. Those not significantly associated with TMD were FGF, G-CSF, TNF $\alpha$ and IL-6. For the purpose of this analysis, we selected the two cytokines in which odds of TMD increased by $\geq 50 \%$ per standard deviation increase in cytokine concentration. One cytokine was IL-1Ra; a potent inhibitor of two proinflammatory cytokines - IL-1alpha and IL-1beta. The other, MCP-1, a chemokine, serves multiple functions including a role in the pathophysiology of allergy and activation of histamine release in basophils. 3,43

\section{Psychological measures}

We classified psychological vulnerability with three factors: psychological stress, trait anxiety and history of depression. Psychological stress was evaluated with the 10-item Perceived Stress Scale (PSS) ${ }^{11}$ that measures the extent to which respondents consider their lives to have been unpredictable, uncontrollable, and overloaded during the preceding month. Responses were made on a five-point scale of frequency ranging from "never" to "very often". Positive items were reversed scored before all responses were summed to yield an overall scale score where higher scores denote greater psychological distress. The 20statement trait anxiety subscale of the Spielberger State and Trait Anxiety Inventory for adults $^{58}$ was administered to measure this stable, enduring component of anxiety. Responses were made on a four-point scale of frequency ranging from "not at all" to "very much so". A single question in the medical history questionnaire asked whether or not participants had ever taken antidepressant medication (yes/no). This question serves as a proxy for lifetime history of depressive symptoms. Given that our interest was the study of chronic TMD, we were less interested in existing clinical depressive symptoms than in lifetime history of treatment for depression because risk of developing chronic TMD is likely to be influenced by exposures over a long period.

\section{Statistical analyses}

Analysis was guided by a directed acyclic graph (Figure 1). For young adults the graph depicts an indirect effect of cigarette smoking on TMD that is mediated by an inflammation or allergy pathway. The same pathways for older adults are depicted to bypass smoking. A binary logistic regression model was used to assess the association between smoking and TMD. Odds ratios were calculated as estimates of the strength of association and 95\% confidence intervals for the odds ratios signified the precision of the odds ratio estimates. Associations were deemed statistically significant when the $95 \%$ confidence interval excluded the null value of 1.0. To test the study hypothesis that the association between smoking and TMD was modified by age, we dichotomized age ( $<30$ versus $\geq 30$ years) after fully exploring the age and TMD relationship. For descriptive purposes, odds of TMD were compared between tertiles of cytokine concentrations and scores for perceived stress and trait anxiety. In multivariable analysis these continuous variables were standardized so that the resulting odds ratios estimated the relative change in odds of TMD associated with one standard deviation of change in the continuous measure. Decisions regarding confounding were based on 1) whether the covariate is associated with both smoking and TMD case status, and 2) whether inclusion of the covariate produces a change of $\geq 10 \%$ in in the odds ratio for the association between smoking and TMD.

Because only a small number of participants were current smokers (19 cases and 9 controls), analyses of smoking combined former and current smokers into a single group labeled "ever smokers". To investigate allergic conditions, a composite variable was computed that 
summed the number of allergic conditions reported to yield a possible range from zero (no allergic conditions) to four allergy conditions.

To test the second aim, odds of TMD was modeled through a sequence of four logistic regression models. Model 1 contained dichotomized smoking, dichotomized age, and their interaction term. Model 2 added the composite variable for allergy-related conditions. Model 3 added the cytokines, and Model 4 added the psychological variables. The purpose of this sequential model building was to quantify the extent to which each model attenuated the odds ratio for smoking in each age stratum. This would determine whether the added variables act as mediators between smoking and TMD in early adulthood. To illustrate how adjustment for covariates altered age-specific associations between smoking and TMD in this sample, the predicted proportion of TMD cases was calculated using parameter estimates from Model 1 (unadjusted) and Model 4 (fully-adjusted), and the proportions were plotted. While the predicted probabilities are valid estimates for this study sample, they should not be interpreted as population estimates of prevalence because the overall proportion of cases was specified by the study design that purposefully selected approximately equal numbers of cases and controls.

To test the generalizability of an age effect on the smoking-TMD relationship, secondary analyses were undertaken using two population-based, nationally representative epidemiological surveys of adults in the United States and Australia. These surveys were the 2007-2009 National Health Interview Survey (NHIS) and the 2004-2006 National Survey of Adult Oral Health in the U.S. and Australia. ${ }^{57}$ Orofacial pain was self-reported in both surveys. Analyses were limited to females for the purpose of comparison with this study.

For the NHIS dataset, orofacial pain symptoms were evaluated with the question, "During the past three months, did you have facial ache or pain in the jaw muscles or the joint in front of the ear?" Response categories were Yes/No/Don't know. We estimated the prevalence of facial pain for various subpopulations that are defined by the crossclassification of age and smoking status. Since the collection of NHIS data is based on a multistage complex survey design and since our focus was confined to adults, we used the adult sampling weights to obtain unbiased estimates of facial pain prevalence and valid standard errors. Specifically, we combined data sets from 2007 to 2009 and divided the sampling weights by three. Adults with missing facial pain response were omitted from analyses.

In the Australian national survey, prevalence of orofacial pain symptoms was determined from seven screening questions that had been validated in a Canadian study. ${ }^{34}$ Three questions asked about pain in the jaws, jaw joint or pre-auricular region and four questions addressed jaw function disturbance such as difficulty opening the mouth wide and freely. Responses of "yes" or "no" were recorded for each symptom in a self-completed questionnaire. The case definition required one or more affirmative response to the pain questions and at least one affirmative response to the jaw function disturbance questions. In data analysis, survey estimation commands corrected the standard errors of estimates by the Taylor series linearization method to take account of the complex survey design.

Data were analyzed in STATA I/C statistical software, version 11.1 IC (Stata Corporation, Texas) and results reported for 133 cases and 166 controls with complete data.

\section{Results}

The mean age of cases was 36.4 years $(95 \% \mathrm{CI}=34.3,38.6)$ compared with 28.7 years for controls $(95 \%=27.1,30.3)$. The older category of age was associated with greater odds of TMD (Table 1). One third (37\%) of cases reported having heard about the study through the 
UNC orofacial pain clinic; the remainder of cases and nearly all controls $(98 \%)$ responded to advertisements and other methods of recruitment.

Compared to lifetime non-smokers, current smokers had three times the odds of TMD (odds ratio $[\mathrm{OR}]=3.33,95 \% \mathrm{CI} 1.44,7.70$ ) while former smokers had twice the odds. Higher concentrations of IL-1Ra and MCP-1 were associated with higher odds of TMD in a doseresponse relation. Likewise perceived stress and trait anxiety were associated with TMD in a dose-response relation. All four allergy-related conditions were positively and strongly associated with TMD. When the allergy-related conditions were summed, $16.7 \%$ of controls reported having all four conditions compared with $83.3 \%$ of TMD cases $(\mathrm{Chi} 2,(4 \mathrm{df})=$ 48.901, $\mathrm{P}<0.001)$.

Examination of the stratum-specific odds ratios (Table 2) revealed that compared to lifetime non-smokers, ever smokers had higher odds of TMD ( $\mathrm{OR}=4.14,95 \%$ CI: $1.57,11.35)$ in the aged 18 to 29 stratum but the relationship was non-significant in the older stratum. (OR $=1.23,95 \%$ CI: $0.55,2.78)$ The Breslow-Day test for homogeneity $(\mathrm{P}=0.038)$ confirmed that the smoking effect differed significantly across age strata.

Greater concentrations of IL-1Ra and MCP-1, a lifetime history of skin rashes or sinus trouble were associated with older age. Smoking was more frequent in older than younger people (Table 3). Among those who had ever smoked relative to never smoked, we observed higher concentrations of cytokines, greater perceived stress and greater use of antidepressant medication, history of allergies, skin rashes sinus trouble and antihistamine use.

Mean IL-1Ra concentrations did not differ between subjects with and without history of allergy-related conditions (Table 4). However mean MCP-1 levels were significantly higher in subjects with history of an allergy-related condition.

The effect modification of age on the smoking and TMD relationship presented in Model 1 (Table 5) was attenuated following adjustment for allergy-related conditions in Model 2. After additional adjustment for the cytokine mediators in Model 3 and the psychological variables in Model 4 the association between smoking and TMD in people aged <30 years was rendered non-significant $(\mathrm{OR}=2.28,95 \% \mathrm{CI}=0.81,6.43)$. Furthermore, the interaction between smoking and age was statistically non-significant. This attenuation of the smoking effect is depicted in Fig. $2 \mathrm{a}$ (unadjusted) and $2 \mathrm{~b}$ (adjusted). Here the unadjusted findings from Model 1 show a lack of overlap in 95\% confidence intervals for proportion of cases between smokers and non-smokers in the young stratum (Fig 2a). However, 95\% CIs overlap (Fig $2 b$ ) in this younger age group when the estimates are adjusted using the variables listed for from Model 4 in Table 5.

Secondary analyses of the National Health Interview Survey (2007-2009) in the United States and the National Survey of Adult Oral Health (2004-2006) in Australia confirmed a relationship between smoking and orofacial pain in females (Figures $3 a$ and $3 b$ ). Again the effect was strongest in younger versus older females, although the threshold age at which smoking ceased to have an effect appeared to be older in these national surveys than in our case control study. The effect modification was significant in the United States $(\mathrm{P}<0.001)$ but not in Australia $(\mathrm{P}=0.811)$.

\section{Discussion}

To the best of our knowledge this is the first study to have examined the relationship between smoking and TMD in age-specific strata. The key finding was that a history of cigarette smoking was strongly associated with TMD, but only among young adults. Specifically in this case control study, smokers aged 18 to 29 years, had four times the odds 
of having TMD when compared with 18-29 year old non-smokers. In adults aged 30 to 60 years, TMD case status had no association with smoking status.

The second major contribution of this study is the first reported finding of an association between any history of allergy-related conditions and TMD. We showed the effect of smoking on TMD in young adults was attenuated $20 \%$ after adjustment for four allergyrelated conditions. The effect was further attenuated $45 \%$ to statistical non-significance after additional adjustment for cytokines and psychological profile.

Our finding that age modified the effect of smoking on TMD is in accordance with previous studies of low back pain. Pooled estimates from a meta-analysis showed that the association between current smoking and incident low back pain was stronger in adolescence (OR $=1.82,95 \% \mathrm{CI}=1.12,2.33)$ than in adults $(\mathrm{OR}=1.16 ; 95 \% \mathrm{CI}=1.02,1.32) .{ }^{55}$

Our results also build on evidence of an association between allergy and chronic pain. In the third US National Health and Nutrition Examination Survey, adults aged 20-39 with any history of asthma, hay fever and other allergies were 50\% more likely to report low back pain than 20-39 year olds without allergies. ${ }^{24}$ Elsewhere a case control study of vulvodynia showed that odds of the condition were elevated between 2.0 -fold to 2.5 -fold in women with a history of any of seasonal allergies, reactions to insect bites or hives. In that study the selfreported allergy conditions preceded the first report of vulvar pain. ${ }^{21}$ The authors suggested that an altered immune-inflammatory response to environmentally induced allergic reactions was a possible explanatory mechanism. And in the 51,383 Head-Hunt Study participants, headache was 1.5 times more likely among those with asthma, asthma related symptoms, hay fever and chronic bronchitis. ${ }^{2}$ Based on their findings from a population-based study, Hurwitz and Morgenstern hypothesized that hypersensitivity reactions evoke dysfunctional reactivity of the hypothalamic-pituitary-adrenal axis to psychological stress with consequences for chronic pain. ${ }^{24} \mathrm{We}$ found that an inflammatory response and allergic conditions had independent effects on odds of TMD in young adult smokers (Model 3, Table 4). In young adults, adjustment for inflammation as indexed by two cytokines, a history of allergy-related conditions, and psychological profile fully accounted for the effect of smoking on TMD.

In line with results from previous clinical studies, ${ }^{16,45,44,46}$ we found that levels of the cytokines MCP-1 and IL-1Ra were associated with increased odds of TMD. MCP-1 is a chemotactic cytokine expressed in a variety of cell types, including leukocytes in the periphery ${ }^{70}$ and neurons in the central nervous system ${ }^{67}$. IL-1Ra is member of the interleukin-1 cytokine family that is largely expressed in macrophages and epithelial cells 22 as well as in brain. ${ }^{32} \mathrm{IL}-1$ Ra binds the proinflammatory cytokines interleukin-1 $\alpha$ (IL-1 $\left.\alpha\right)$ and interleukin-1 $\beta$ (IL-1 $\beta$ ), thus inhibiting their activity. ${ }^{14}$ Studies in animal models demonstrate that expression of both MCP-1 and IL-1Ra is strongly upregulated following injury or inflammation. ${ }^{25,37,64,67}$ A mechanistic role for MCP-1 in chronic pain is supported by recent studies showing that MCP-1 is able to excite sensory neurons. ${ }^{67}$ While a mechanistic role for the anti-inflammatory cytokine IL-1Ra in chronic pain is less clear, its synthesis and release is stimulated by the proinflammatory cytokine IL-1. Kinetic studies have demonstrated that the balance between IL-1Ra and IL-1 production is dependent upon the phase of the inflammatory response. ${ }^{59}$ Thus, IL-1Ra may be viewed as a marker of IL-1, which is deemed a prototypical proinflammatory cytokine well known for its ability to activate and sensitize nociceptors 28 as well as drive HPA-related stress responses. ${ }^{19}$ Collectively, these results suggest that MCP-1 and IL-1Ra/IL-1 inflammatory pathways contribute to TMD. 
One explanation for why the smoking and TMD relationship was found only in young adults is that one or more of the explanatory factors operate differently between young and older individuals. Support of this supposition comes from a study of the Swiss adult population, where odds of being atopic decreased by $21.0 \%$ on average with every 10 -year increase in age. ${ }^{68}$

Little is known about exposure to tobacco smoke and IL-1Ra and MCP-1 concentrations in humans. One report of a positive association between smoking and plasma concentration of IL-1Ra in healthy subjects ${ }^{13}$ conflicted with the finding of higher IL-1ra concentrations in non-smokers than smokers. ${ }^{39}$ In the periodontal literature a comparison of gingival crevice fluid IL-1ra concentrations in smokers and non-smokers, found smokers had significantly higher IL-1ra concentrations in healthy periodontal sites than non-smokers. However in subjects with deep bleeding periodontal sites, smokers had significantly lower IL-1ra concentrations than non-smokers. ${ }^{51} \mathrm{~A}$ recent experimental study showed that cigarette smoking and nicotine significantly induced MCP-1 expression in pancreatic ductal adenocarcinoma cells. ${ }^{30}$ In humans, MCP-1 concentration was significantly elevated in healthy smokers compared with healthy former smokers. ${ }^{9}$

The active ingredients in tobacco smoke that alter pain perception are not fully understood, but it is generally assumed that nicotine is the primary substance that modifies pain perception. The effects of nicotine on pain perception are complex (for a review see Shi et, al., 2010). ${ }^{54}$ Experimental studies that use brief noxious stimuli following the ingestion of nicotine provide evidence that nicotine has analgesic properties. Chronic exposure to tobacco smoke leads to changes in pain perception such that smokers deprived of nicotine show greater sensitivity to pain evoking stimuli. ${ }^{42,56}$ In the postoperative pain setting, the administration of nicotine produces analgesia in nicotine naïve participants and produces little or no analgesic effect in smokers. ${ }^{20,62}$ The chronic exposure to nicotine can induce biological states that produce hyperalgesia and dependency similar to that seen with the chronic exposure to opioids when nicotine levels are acutely reduced. We speculate that the diminished effect of smoking at ages older than 30 results from a diminished effect of smoking on the production of proinflammatory substances, which diminishes the likelihood of developing post-nicotine exposure hyperalgesic states.

The risk of chronic TMD in young former or current smokers was more than four times as high compared with older adults who had never smoked. Simultaneous adjustment for psychological profile, cytokines and allergy conditions approximately halved this effect and rendered the effect of smoking in young adults statistically non-significant showing these to be explanatory factors for excess risk. Nonetheless in the fully adjusted model, allergy conditions, interleukin-1 receptor antagonist and trait anxiety score remained significantly associated with TMD in young adults showing these to be independent risk indicators beyond the effects of tobacco. These findings highlight noteworthy age-related differences. For instance, ever smokers were twice as likely as life-time non-smokers to perceive high psychological distress but this effect was evident only in young adults. In addition, eversmokers were twice as likely as non-smokers to have a history of allergy conditions and to use antihistamines, and again these effects were more pronounced in young versus older adults. Furthermore ever smokers had four times the odds of chronic TMD than lifetime non-smokers, but only among young adults. This consistency of evidence suggests that the relationships between smoking, psychological stress, allergy and TMD risk differ on the basis of age; indeed these case control results formally confirmed that age significantly modified the smoking and TMD relationship. Of these risk indicators in young adults, smoking may be the most easily modified and smoking cessation may have long-term benefits for inflammatory function, psychological health and conditions such as allergic 
rhinitis ${ }^{33}$ and urticaria. ${ }^{31}$ However it is not known whether smoking cessation might negate any analgesic effects of nicotine on TMD pain.

Strengths of this study were use of the well-validated Research Diagnostic Criteria for determining TMD case status and the diverse dataset that included psychological instruments and cytokines. Another major strength was that we were able to reproduce our findings in two large national surveys with representative samples of female adults. The self-reported nature of TMD symptoms in these national surveys inevitably results in overestimation or under-estimation of TMD prevalence. Despite this misclassification, the relationship was sufficiently strong to replicate our case control findings, which strengthened this study's external validity.

Nonetheless, several possible limitations should be considered when interpreting our study findings. This case-control study design and the cross-sectional design of the national survey did not establish a temporal sequence between smoking and onset of TMD. It is plausible that some people might have begun to smoke as a consequence of developing TMD symptoms. Moreover anxiety and psychological stress may make smoking cessation efforts more difficult, as smokers with TMD may rely on tobacco to elevate mood and relieve comorbid depressive symptoms. This "reverse causation" might account for some of the observed association between smoking and TMD. However, the evidence from prospective cohort studies of other chronic pain conditions suggests that the predominant effect is in the expected causal direction. ${ }^{55}$

The degree to which TMD cases and controls were misclassified during examination is unrelated to the exposures of interest in this study (tobacco use, psychological profile, cytokines, allergy conditions). Therefore any misclassification of case status would produce non-differential bias, which does not pose a concern to the strength or direction of associations reported in this study. The only adverse impact of misclassification is increased variance (i.e. widened $95 \%$ CIs) around our estimates. A related concern with case-control studies is whether controls are selected from the same source population that gives rise to the cases. ${ }^{47}$ Yet, most controls heard about the study through the same methods reported by nearly all cases, suggesting that the majority of cases and controls came from the community at large.

Due to the relatively small number of current smokers, we limited the analysis of effect modification to a binary exposure measure. Hence, the risk of TMD associated with smoking cannot be attributed solely to elevated concentrations of nicotine or other substances inhaled in cigarette smoke because there is no such elevation in former smokers. Yet, the bivariate findings in Table 1 show that the odds ratio for TMD is greater in current smokers than in former-smokers. This suggests that exposure to tobacco itself confers an additional risk for TMD, in addition to behavioral characteristics or other antecedents of smoking behavior. The small number of current smokers in this study reduces precision of estimates making interpretation of the strength of the smoking and TMD relationship more difficult.

Finally, our measures of allergy-related conditions were taken by convenience from the medical history questionnaire and were not planned in advance. However in future analyses we will examine IgE levels in stored blood. We used history of antidepressant medication as a marker of psychological profile. This may introduce misclassification as chronic pain sufferers are sometimes prescribed antidepressants for pain control as well as fatigue, or sleep disturbances. 
This study has shed light on a complex interplay of allergy, cytokines, and smoking in a case control study of chronic TMD. Understanding the mechanisms underlying these relationships can best be addressed in large prospective studies of chronic TMD pain.

\section{Acknowledgments}

Disclosures This study was supported by NIH grants DE016558 (L.D., PI) NS045685 (W.M., PD), NIH/NCRR KL2 RR025746 (A.N.), and NIH/NINDS PO1 NS045685-061A (A.N., G.S., L.D., and W.M.).

\section{References}

1. Aamodt AH, Stovner LJ, Hagen K, Brathen G, Zwart J. Headache prevalence related to smoking and alcohol use. The Head-HUNT Study. Eur J Neurol. 2006; 13:1233-1238. [PubMed: 17038038]

2. Aamodt AH, Stovner LJ, Langhammer A, Hagen K, Zwart JA. Is headache related to asthma, hay fever, and chronic bronchitis? The Head-HUNT Study. Headache. 2007; 47:204-212. [PubMed: 17300360]

3. Alam R, Kampen G. Cytokines in allergic inflammation. Clin Allergy Immunol. 2002; 16:255-274. [PubMed: 11577542]

4. Barbee RA, Halonen M, Kaltenborn W, Lebowitz M, Burrows B. A longitudinal study of serum IgE in a community cohort: correlations with age, sex, smoking, and atopic status. J Allergy Clin Immunol. 1987; 79:919-927. [PubMed: 3584747]

5. Barkhordari E, Rezaei N, Ansaripour B, Larki P, Alighardashi M, Ahmadi-Ashtiani HR, Mahmoudi M, Keramati MR, Habibollahi P, Bashashati M, Ebrahimi-Daryani N, Amirzargar AA.

Proinflammatory cytokine gene polymorphisms in irritable bowel syndrome. J Clin Immunol. 2010; 30:74-79. [PubMed: 19844779]

6. Bazzichi L, Rossi A, Massimetti G, Giannaccini G, Giuliano T, De Feo F, Ciapparelli A, Dell'Osso L, Bombardieri S. Cytokine patterns in fibromyalgia and their correlation with clinical manifestations. Clin Exp Rheumatol. 2007; 25:225-230. [PubMed: 17543146]

7. Bischoff SC, Krieger M, Brunner T, Dahinden CA. Monocyte chemotactic protein 1 is a potent activator of human basophils. J Exp Med. 1992; 175:1271-1275. [PubMed: 1569397]

8. Blanco I, Beritze N, Arguelles M, Carcaba V, Fernandez F, Janciauskiene S, Oikonomopoulou K, de Serres FJ, Fernandez-Bustillo E, Hollenberg MD. Abnormal overexpression of mastocytes in skin biopsies of fibromyalgia patients. Clin Rheumatol. 2010

9. Capelli A, Di Stefano A, Gnemmi I, Balbo P, Cerutti CG, Balbi B, Lusuardi M, Donner CF. Increased MCP-1 and MIP-1beta in bronchoalveolar lavage fluid of chronic bronchitics. Eur Respir J. 1999; 14:160-165. [PubMed: 10489845]

10. Chaiton MO, Cohen JE, O'Loughlin J, Rehm J. A systematic review of longitudinal studies on the association between depression and smoking in adolescents. BMC Public Health. 2009; 9:356. [PubMed: 19772635]

11. Cohen S, Kamarck T, Mermelstein R. A global measure of perceived stress. J Health Soc Behav. 1983; 24:385-396. [PubMed: 6668417]

12. Croghan IT, Bronars C, Patten CA, Schroeder DR, Nirelli LM, Thomas JL, Clark MM, Vickers KS, Foraker R, Lane K, Houlihan D, Offord KP, Hurt RD. Is smoking related to body image satisfaction, stress, and self-esteem in young adults? Am J Health Behav. 2006; 30:322-333. [PubMed: 16712446]

13. Cullup H, Middleton PG, Duggan G, Conn JS, Dickinson AM. Environmental factors and not genotype influence the plasma level of interleukin-1 receptor antagonist in normal individuals. Clin Exp Immunol. 2004; 137:351-358. [PubMed: 15270852]

14. Dinarello CA. The interleukin-1 family: 10 years of discovery. FASEB J. 1994; 8:1314-1325. [PubMed: 8001745]

15. Dworkin SF, LeResche L. Research diagnostic criteria for temporomandibular disorders: review, criteria, examinations and specifications, critique. J Craniomandib Disord. 1992; 6:301-355. [PubMed: 1298767] 
16. Fang PK, Ma XC, Ma DL, Fu KY. Determination of interleukin-1 receptor antagonist, interleukin-10, and transforming growth factor-beta1 in synovial fluid aspirates of patients with temporomandibular disorders. J Oral Maxillofac Surg. 1999; 57:922-928. discussion 928-929. [PubMed: 10437719]

17. Gangl K, Reininger R, Bernhard D, Campana R, Pree I, Reisinger J, Kneidinger M, Kundi M, Dolznig H, Thurnher D, Valent P, Chen KW, Vrtala S, Spitzauer S, Valenta R, Niederberger V. Cigarette smoke facilitates allergen penetration across respiratory epithelium. Allergy. 2009; 64:398-405. [PubMed: 19120070]

18. Gordon C, Wofsy D. Effects of recombinant murine tumor necrosis factor-alpha on immune function. J Immunol. 1990; 144:1753-1758. [PubMed: 2307839]

19. Goshen I, Yirmiya R, Iverfeldt K, Weidenfeld J. The role of endogenous interleukin-1 in stressinduced adrenal activation and adrenalectomy-induced adrenocorticotropic hormone hypersecretion. Endocrinology. 2003; 144:4453-4458. [PubMed: 12960098]

20. Habib AS, White WD, El Gasim MA, Saleh G, Polascik TJ, Moul JW, Gan TJ. Transdermal nicotine for analgesia after radical retropubic prostatectomy. Anesth Analg. 2008; 107:999-1004. [PubMed: 18713920]

21. Harlow BL, He W, Nguyen RH. Allergic reactions and risk of vulvodynia. Ann Epidemiol. 2009; 19:771-777. [PubMed: 19825458]

22. Haskill S, Martin G, Van Le L, Morris J, Peace A, Bigler CF, Jaffe GJ, Hammerberg C, Sporn SA, Fong S, et al. cDNA cloning of an intracellular form of the human interleukin 1 receptor antagonist associated with epithelium. Proc Natl Acad Sci U S A. 1991; 88:3681-3685. [PubMed: 1827201]

23. Holla LI, Mrazek F, Petrek M. MCP-1 and CCR2 gene polymorphisms in Czech patients with allergic disorders. Int J Immunogenet. 2009; 36:69-72. [PubMed: 19055601]

24. Hurwitz EL, Morgenstern H. Cross-sectional associations of asthma, hay fever, and other allergies with major depression and low-back pain among adults aged 20-39 years in the United States. Am J Epidemiol. 1999; 150:1107-1116. [PubMed: 10568627]

25. Jeon SM, Lee KM, Park ES, Jeon YH, Cho HJ. Monocyte chemoattractant protein-1 immunoreactivity in sensory ganglia and hindpaw after adjuvant injection. Neuroreport. 2008; 19:183-186. [PubMed: 18185105]

26. Keil T, Lau S, Roll S, Gruber C, Nickel R, Niggemann B, Wahn U, Willich SN, Kulig M. Maternal smoking increases risk of allergic sensitization and wheezing only in children with allergic predisposition: longitudinal analysis from birth to 10 years. Allergy. 2009; 64:445-451. [PubMed: 19170671]

27. Kocer A, Kocer E, Memisogullari R, Domac FM, Yuksel H. Interleukin-6 Levels in Tension Headache Patients. Clin J Pain. 2010; 26:690-693. [PubMed: 20664340]

28. Kress, M.; Sommer, C. Neuroimmunology and Pain: Peripheral Effects of Proinflammatory Cytokines. In: Brune, K.; Handwerker, HO., editors. Hyperalgesia: Molecular Mechanisms and Clinical Implications. Vol. Vol 30. IASP Press; 2004. p. 57-65.

29. Latthe P, Mignini L, Gray R, Hills R, Khan K. Factors predisposing women to chronic pelvic pain: systematic review. BMJ. 2006; 332:749-755. [PubMed: 16484239]

30. Lazar M, Sullivan J, Chipitsyna G, Aziz T, Salem AF, Gong Q, Witkiewicz A, Denhardt DT, Yeo CJ, Arafat HA. Induction of monocyte chemoattractant protein-1 by nicotine in pancreatic ductal adenocarcinoma cells: role of osteopontin. Surgery. 2010; 148:298-309. [PubMed: 20579680]

31. Lee IW, Ahn SK, Choi EH, Lee SH. Urticarial reaction following the inhalation of nicotine in tobacco smoke. Br J Dermatol. 1998; 138:486-488. [PubMed: 9580805]

32. Licinio J, Wong ML, Gold PW. Localization of interleukin-1 receptor antagonist mRNA in rat brain. Endocrinology. 1991; 129:562-564. [PubMed: 1829036]

33. Lin SY, Reh DD, Clipp S, Irani L, Navas-Acien A. Allergic rhinitis and secondhand tobacco smoke: A population-based study. Am J Rhinol Allergy. 2011; 25:66-71.

34. Locker D, Slade G. Prevalence of symptoms associated with temporomandibular disorders in a Canadian population. Community Dent Oral Epidemiol. 1988; 16:310-313. [PubMed: 3263254]

35. McKenzie M, Olsson CA, Jorm AF, Romaniuk H, Patton GC. Association of adolescent symptoms of depression and anxiety with daily smoking and nicotine dependence in young adulthood: 
findings from a 10-year longitudinal study. Addiction. 2010; 105:1652-1659. [PubMed: 20707783]

36. Melis M, Lobo SL, Ceneviz C, Ruparelia UN, Zawawi KH, Chandwani BP, Mehta NR. Effect of cigarette smoking on pain intensity of TMD patients: a pilot study. Cranio. 2010; 28:187-192. [PubMed: 20806737]

37. Menetski J, Mistry S, Lu M, Mudgett JS, Ransohoff RM, Demartino JA, Macintyre DE, Abbadie C. Mice overexpressing chemokine ligand 2 (CCL2) in astrocytes display enhanced nociceptive responses. Neuroscience. 2007; 149:706-714. [PubMed: 17870246]

38. Merskey, H.; Bogduk, N., editors. Classification of Chronic Pain, Second Edition, IASP Task Force on Taxonomy. IASP Press; Seattle: 1994.

39. Mikuniya T, Nagai S, Tsutsumi T, Morita K, Mio T, Satake N, Izumi T. Proinflammatory or regulatory cytokines released from BALF macrophages of healthy smokers. Respiration. 1999; 66:419-426. [PubMed: 10516538]

40. Movat HZ. Tumor necrosis factor and interleukin-1: role in acute inflammation and microvascular injury. J Lab Clin Med. 1987; 110:668-681. [PubMed: 3316455]

41. Nam SY, Kim BC, Ryu KH, Park BJ. Prevalence and risk factors of irritable bowel syndrome in healthy screenee undergoing colonoscopy and laboratory tests. J Neurogastroenterol Motil. 2010; 16:47-51. [PubMed: 20535326]

42. Nesbitt PD. Smoking, physiological arousal, and emotional response. J Pers Soc Psychol. 1973; 25:137-144. [PubMed: 4688163]

43. Nickel R, Beck LA, Stellato C, Schleimer RP. Chemokines and allergic disease. J Allergy Clin Immunol. 1999; 104:723-742. [PubMed: 10518815]

44. Ogura N, Satoh K, Akutsu M, Tobe M, Kuyama K, Kuboyama N, Sakamaki H, Kujiraoka H, Kondoh T. MCP-1 production in temporomandibular joint inflammation. J Dent Res. 89:11171122. [PubMed: 20647497]

45. Ogura N, Satoh K, Akutsu M, Tobe M, Kuyama K, Kuboyama N, Sakamaki H, Kujiraoka H, Kondoh T. MCP-1 production in temporomandibular joint inflammation. J Dent Res. 2010; 89:1117-1122. [PubMed: 20647497]

46. Ogura N, Tobe M, Sakamaki H, Nagura H, Abiko Y, Kondoh T. Tumor necrosis factor-alpha increases chemokine gene expression and production in synovial fibroblasts from human temporomandibular joint. J Oral Pathol Med. 2005; 34:357-363. [PubMed: 15946184]

47. Palla S, Farella M. External validity: a forgotten issue? Int J Prosthodont. 2010; 23:293-294. [PubMed: 20812434]

48. Pamuk ON, Donmez S, Cakir N. The frequency of smoking in fibromyalgia patients and its association with symptoms. Rheumatol Int. 2009; 29:1311-1314. [PubMed: 19152091]

49. Patton GC, Carlin JB, Coffey C, Wolfe R, Hibbert M, Bowes G. Depression, anxiety, and smoking initiation: a prospective study over 3 years. Am J Public Health. 1998; 88:1518-1522. [PubMed: 9772855]

50. Pratt LA, Brody DJ. Depression and smoking in the U.S. household population aged 20 and over, 2005-2008. NCHS Data Brief. 2010:1-8. [PubMed: 20604991]

51. Rawlinson A, Grummitt JM, Walsh TF, Douglas CW Ian. Interleukin 1 and receptor antagonist levels in gingival crevicular fluid in heavy smokers versus non-smokers. J Clin Periodontol. 2003; 30:42-48. [PubMed: 12702110]

52. Rozen TD. A History of Cigarette Smoking Is Associated With the Development of Cranial Autonomic Symptoms With Migraine Headaches. Headache. 2011

53. Sandler NA, Buckley MJ, Cillo JE, Braun TW. Correlation of inflammatory cytokines with arthroscopic findings in patients with temporomandibular joint internal derangements. J Oral Maxillofac Surg. 1998; 56:534-543. discussion 543-534. [PubMed: 9590334]

54. Shi Y, Weingarten TN, Mantilla CB, Hooten WM, Warner DO. Smoking and pain: pathophysiology and clinical implications. Anesthesiology. 2010; 113:977-992. [PubMed: 20864835]

55. Shiri R, Karppinen J, Leino-Arjas P, Solovieva S, Viikari-Juntura E. The association between smoking and low back pain: a meta-analysis. Am J Med. 2010; 123:87, e87-35. [PubMed: 20102998] 
56. Silverstein B. Cigarette smoking, nicotine addiction, and relaxation. J Pers Soc Psychol. 1982; 42:946-950. [PubMed: 7086634]

57. GD, SA Slade; Thomson, KF Roberts; Welfare AIoHa., editors. Australia's dental generations: the National Survey of Adult Oral Health 2004-06. Australian Institute of Health and Welfare; Canberra: 2007. Dental Statistics and Research Series No. 34; No. AIHW cat. no. DEN 165

58. Spielberger, CD.; Gorsuch, RL.; Lushene, RE. Test Manual for the State-Trait Anxiety Inventory. Consulting Psychologists Press; Palo Alto, CA: 1970.

59. Spulber S, Bartfai T, Schultzberg M. IL-1/IL-1ra balance in the brain revisited - evidence from transgenic mouse models. Brain Behav Immun. 2009; 23:573-579. [PubMed: 19258032]

60. Taylor RG, Gross E, Joyce H, Holland F, Pride NB. Smoking, allergy, and the differential white blood cell count. Thorax. 1985; 40:17-22. [PubMed: 3969651]

61. Tobin MC, Moparty B, Farhadi A, DeMeo MT, Bansal PJ, Keshavarzian A. Atopic irritable bowel syndrome: a novel subgroup of irritable bowel syndrome with allergic manifestations. Ann Allergy Asthma Immunol. 2008; 100:49-53. [PubMed: 18254482]

62. Turan A, White PF, Koyuncu O, Karamanliodlu B, Kaya G, Apfel CC. Transdermal nicotine patch failed to improve postoperative pain management. Anesth Analg. 2008; 107:1011-1017. [PubMed: 18713922]

63. Waldie KE, McGee R, Reeder AI, Poulton R. Associations between frequent headaches, persistent smoking, and attempts to quit. Headache. 2008; 48:545-552. [PubMed: 18218010]

64. Wang X, Barone FC, Aiyar NV, Feuerstein GZ. Interleukin-1 receptor and receptor antagonist gene expression after focal stroke in rats. Stroke. 1997; 28:155-161. discussion 161-152. [PubMed: 8996505]

65. Wanman A. Temporomandibular disorders among smokers and nonsmokers: a longitudinal cohort study. J Orofac Pain. 2005; 19:209-217. [PubMed: 16106714]

66. Weingarten TN, Iverson BC, Shi Y, Schroeder DR, Warner DO, Reid KI. Impact of tobacco use on the symptoms of painful temporomandibular joint disorders. Pain. 2009; 147:67-71. [PubMed: 19793624]

67. White FA, Sun J, Waters SM, Ma C, Ren D, Ripsch M, Steflik J, Cortright DN, Lamotte RH, Miller RJ. Excitatory monocyte chemoattractant protein-1 signaling is up-regulated in sensory neurons after chronic compression of the dorsal root ganglion. Proc Natl Acad Sci U S A. 2005; 102:14092-14097. [PubMed: 16174730]

68. Wuthrich B, Schindler C, Medici TC, Zellweger JP, Leuenberger P. IgE levels, atopy markers and hay fever in relation to age, sex and smoking status in a normal adult Swiss population. SAPALDIA (Swiss Study on Air Pollution and Lung Diseases in Adults) Team. Int Arch Allergy Immunol. 1996; 111:396-402. [PubMed: 8957114]

69. Yadav A, Saini V, Arora S. MCP-1: Chemoattractant with a role beyond immunity: A review. Clin Chim Acta. 2010

70. Yoshimura T, Robinson EA, Tanaka S, Appella E, Leonard EJ. Purification and amino acid analysis of two human monocyte chemoattractants produced by phytohemagglutinin-stimulated human blood mononuclear leukocytes. J Immunol. 1989; 142:1956-1962. [PubMed: 2921521]

71. Zvolensky MJ, McMillan KA, Gonzalez A, Asmundson GJ. Chronic musculoskeletal pain and cigarette smoking among a representative sample of Canadian adolescents and adults. Addict Behav. 2010; 35:1008-1012. [PubMed: 20621422] 


\section{Perspective}

This study showed that smoking was associated with TMD risk in females, but only in young adulthood. It replicated this finding in two nationally representative surveys of females in the U.S. and Australia. Findings may alert clinicians to recognize that smoking is a concern for TMD in younger female patients. 


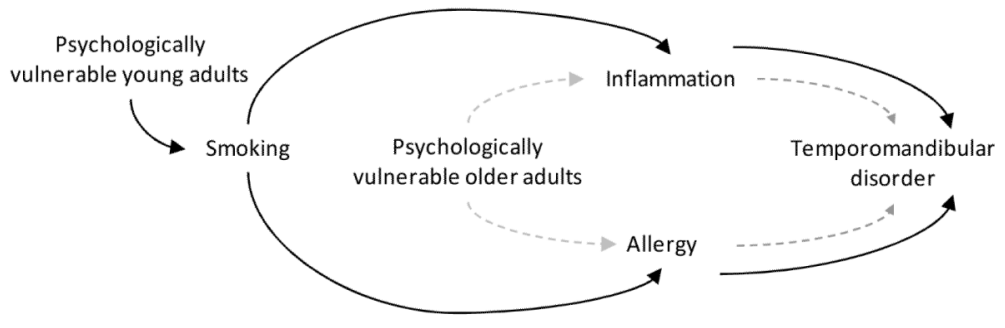

Figure 1.

Directed acyclic graph depicting the pathway between smoking and temporomandibular disorder (TMD) in young (aged <30 years) and older adults defined as psychologically vulnerable (on the basis of psychological stress and trait anxiety scores and a history of antidepressant medication usage).

The solid black line represents the proposed pathway for young adults. It passes through tobacco smoking to inflammation (cytokines IL-1Ra and MCP-1) and allergy (self-report of skin rashes, sinus trouble, allergies or hives, antihistamine use). The dashed gray line represents the causal pathway for older adults, which bypasses smoking. The graph assumes no unmeasured confounders given control for measured variables. 


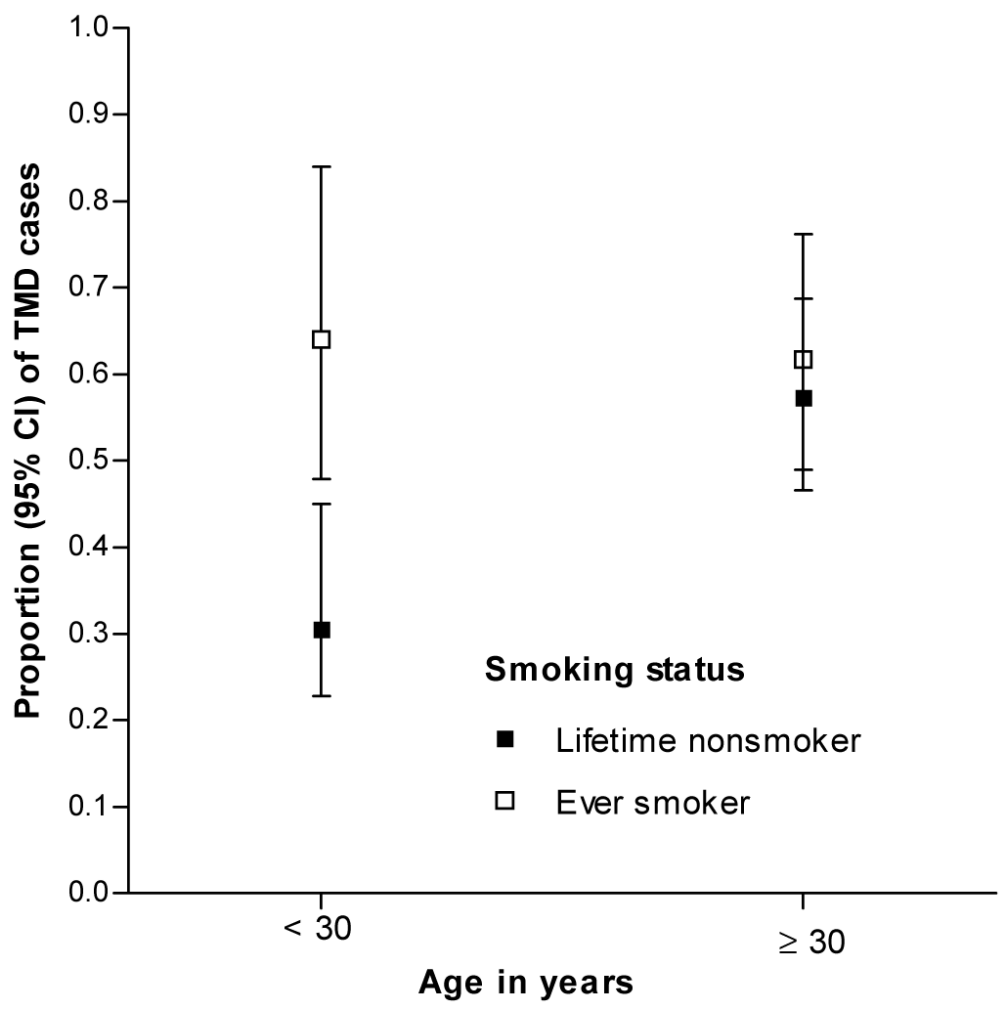

Figure 2a.

Illustration of interaction between age and smoking with no adjustment for covariates.

Parameter estimates from Model 1 of Table 5 were used to calculate predicted proportions of TMD cases within this sample of 299 people in Chapel Hill, USA.P-value for interaction $=0.039$ ) 


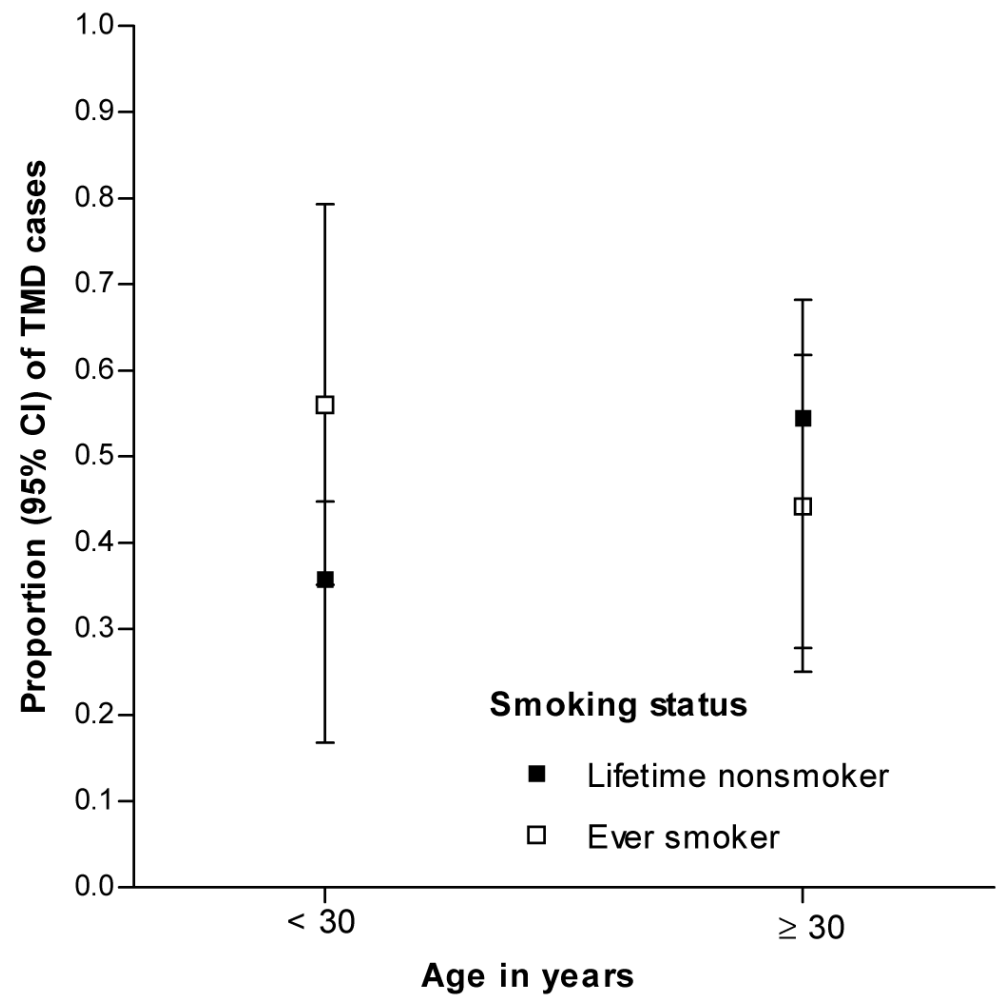

Figure 2b.

Illustration of interaction between age and smoking with adjustment for covariates shown in Model 4 of Table 5: sum of allergies, Interleukin-1 receptor antagonist and monocyte chemotactic protein- 1 concentrations, perceived psychological stress, trait anxiety and lifetime history of antidepressant medication usage. Parameter estimates from Model 5 of Table 5 were used to calculate predicted proportions of TMD cases within this case-control sample of 299 people in Chapel Hill, USA. (P-value for interaction=0.118) 


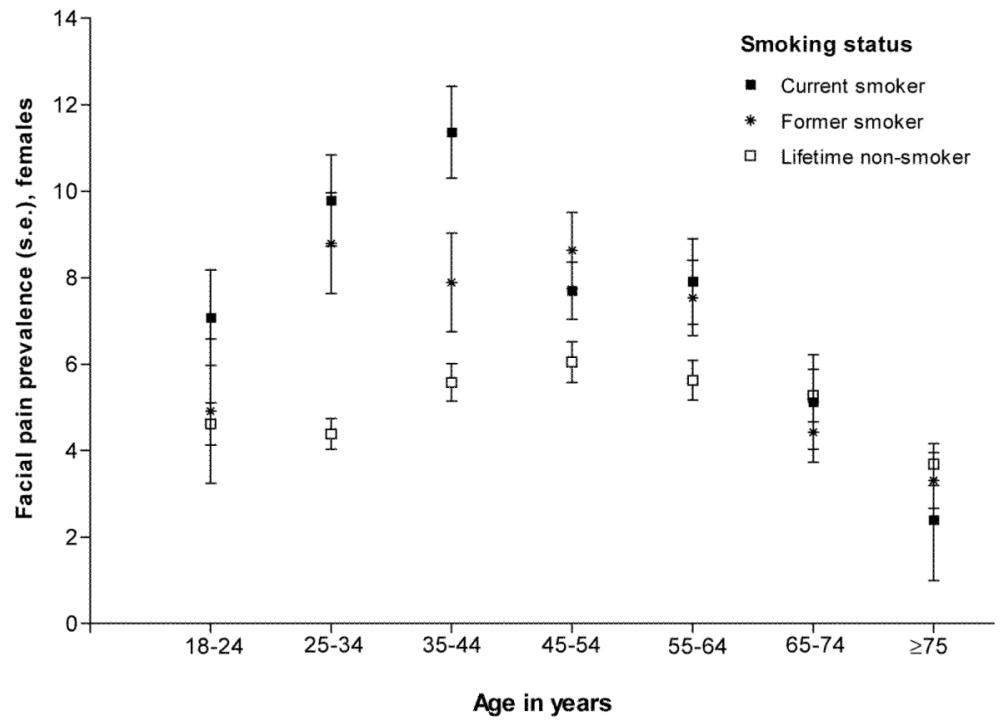

\section{Figure 3a.}

Relationship between smoking status and facial pain across age strata among females living in the United States. Prevalence is the percentage of subjects who answered affirmatively to the question, "During the past three months, did you have facial ache or pain in the jaw muscles or the joint in front of the ear?" Data are nationally representative estimates for female participants aged 18 years and older in the National Health Interview Survey 2007-2009 $(n=40,337)$. P value for the age*smoking interaction $<0.001$ 


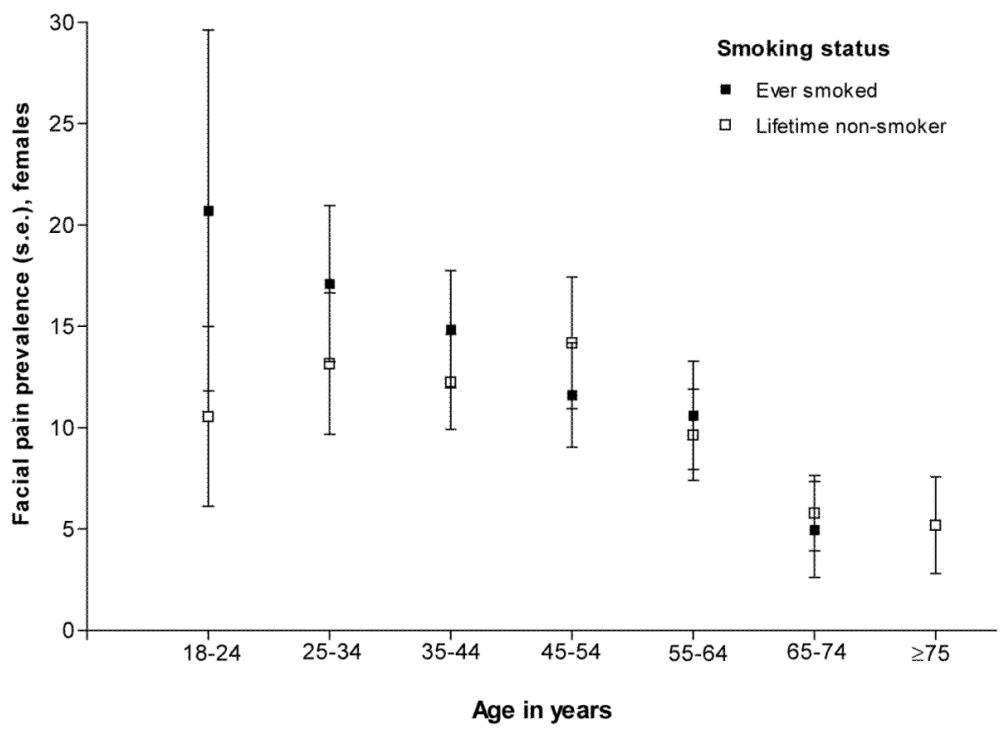

Figure 3b.

Relationship between smoking status and orofacial pain symptoms across age strata among females living in Australia. Prevalence of orofacial pain symptoms was assessed in a selfadministered questionnaire with seven screening questions. Three questions asked about pain in the jaws, jaw joint or pre-auricular region and four questions addressed jaw function disturbance such as difficulty opening the mouth wide and freely. The case definition used in this study required one or more affirmative response to the three pain questions and at least one affirmative response to the four jaw function disturbance questions. Data are nationally representative estimates for females in the National Survey of Adult Oral Health 2004-2006 $(\mathrm{n}=2,461)$. $\mathrm{P}$ value for the age* ${ }^{*}$ smoking interaction $=0.8109$ 


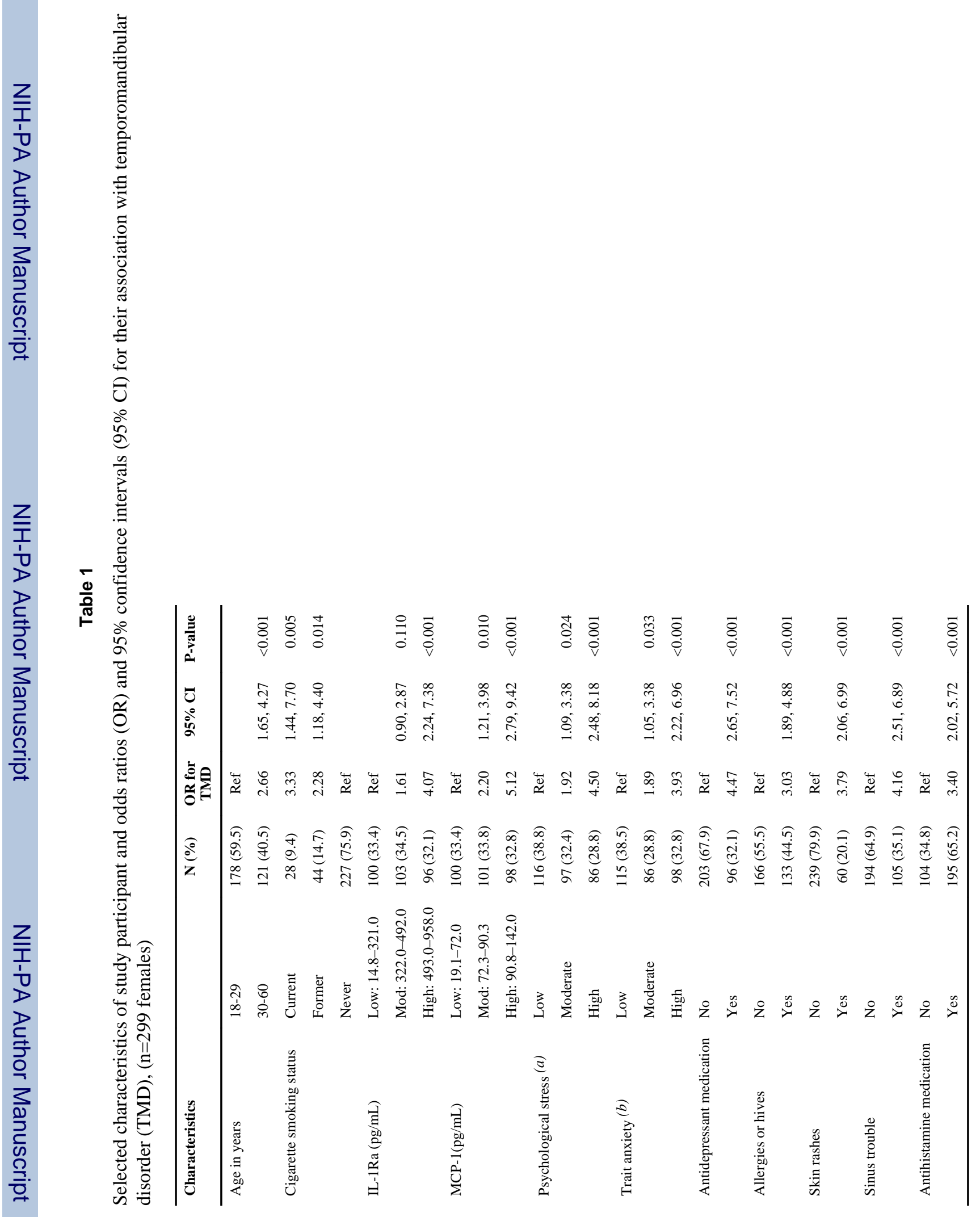


Table 2

Relationship of cigarette smoking exposure to TMD (odds ratio [OR], 95\% confidence interval [95\% CI]), stratified by age.

\begin{tabular}{|c|c|c|c|c|}
\hline & \multicolumn{2}{|r|}{$<30$ years } & \multicolumn{2}{|r|}{$\geq 30$ years } \\
\hline & OR & $95 \% \mathrm{CI}$ & OR & $95 \% \mathrm{CI}$ \\
\hline Ever smoker & 4.14 & $1.57,11.35$ & 1.23 & $0.55,2.78$ \\
\hline Lifetime non-smoker & Ref & & Ref & \\
\hline
\end{tabular}

Breslow-Day test of homogeneity, $\mathrm{P}=0.038$

$95 \%$ confidence interval is from the exact method for contingency tables 


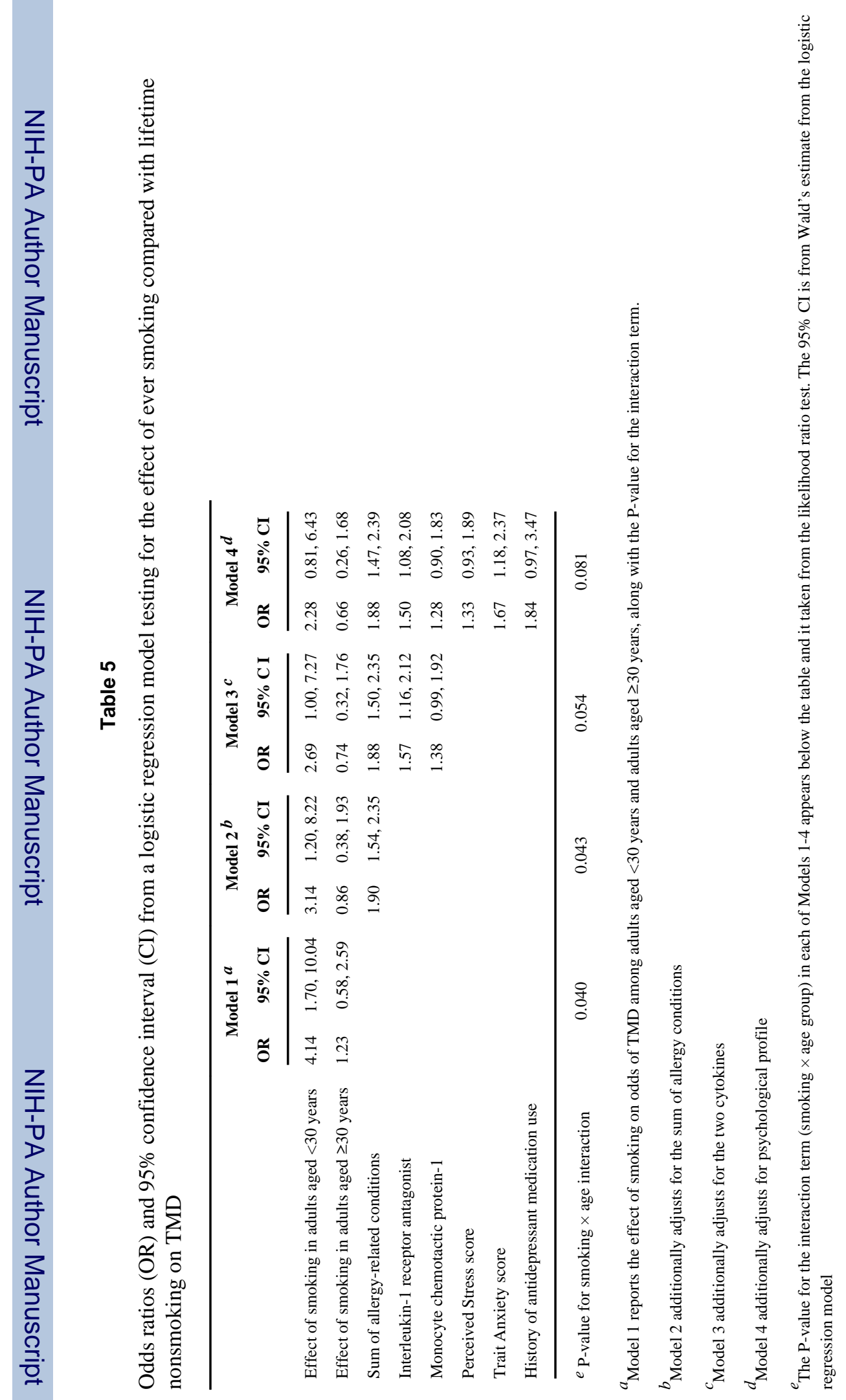

